\title{
Licenciaturas e educação infantil: desafios para a formação inicial
}

Simone Maria de Bastos Nascimento

\author{
Universidade Estadual do \\ Centro-Oeste (Guarapuava, \\ $\mathrm{PR}$, Brasil)
}

Resumo: Este artigo apresenta resultados de projeto de pesquisa que discute a relação entre formação inicial em nível superior e os conhecimentos para atuar na educação infantil adquiridos em cursos de três licenciaturas. 0 objetivo foi investigar se as grades curriculares das licenciaturas apresentam disciplinas que contemplam questões relativas ao atendimento da criança de 0 a 5 anos, bem como problematizar a formação inicial para a docência e identificar desafios para a atuação do profissional na educação infantil. Superar a fragmentação entre os conhecimentos adquiridos na formação inicial e os conhecimentos necessários para a atuação na educação infantil requer romper com estruturas curriculares engessadas que concentram esforços em conhecimentos específicos da área de formação sem formar declaradamente para a docência.

Palavras-chave: Licenciaturas. Formação de professores. Educação infantil. 


\section{INTRODUÇÃO}

Em linhas gerais, pode-se dizer que a formação de professores busca contemplar os saberes necessários ao exercício profissional no sentido da atuação comprometida efetivamente com a formação humana de crianças, adolescentes e jovens. A problematização proposta neste texto envolve as questões relacionadas à formação inicial para a docência na educação infantil a partir do que está posto na legislação educacional acerca da formação mínima para atuar nesse nível de ensino. A Lei de Diretrizes e Bases da Educação Nacional (LDB) (lei n. 9.394/96) indica que, para atuar na educação infantil, o profissional pode ter a formação em qualquer curso de licenciatura, sendo admitida a formação em nível médio na modalidade normal. Ao levar em conta tal proposição, perguntamo-nos como as licenciaturas em áreas específicas têm considerado essa possibilidade incluindo em sua grade curricular disciplinas com conteúdos necessários para essa atuação. No caso do curso de Pedagogia, embora uma avaliação inicial nos dê indícios de que essa formação estaria contemplada, faz-se necessário avaliar mais detidamente em que medida esse aspecto tem efetivamente sido aprofundado no curso.

A fim de refletir sobre tais questões foram analisadas as grades curriculares dos cursos de licenciatura em História, Ciências Biológicas e Pedagogia de uma instituição pública de ensino superior do estado do Paraná. A escolha das duas primeiras licenciaturas a serem analisadas foi realizada de modo aleatório. A análise da licenciatura em Pedagogia se deu pelo fato de esta, a partir de 2006, assumir em nível superior a formação de professores para atuar na primeira etapa da educação básica, ou seja, na educação infantil. Os dados coletados foram examinados em contraponto com as Diretrizes Curriculares Nacionais para a Formação de Professores da Educação Básica (instituídas pela Resolução CNE/CP n. 1, de 18 de fevereiro de 2002), as Diretrizes Curriculares Nacionais para o curso de Pedagogia (instituídas pela Resolução CNE/CP n. 1, de 15 de maio de 2006) e as Diretrizes Curriculares Nacionais para a Educação Infantil (instituídas pela Resolução CNE/CEB n. 5, de 17 de dezembro de 2009).

Além disso, foram consideradas as pesquisas desenvolvidas por Gatti (2000; 2010) sobre formação inicial nos cursos de licenciatura, os estudos de Brzezinski (2007) referentes aos desafios que envolvem a valorização dos profissionais da educação básica no que diz respeito às políticas de formação, bem como de autores da educação infantil que ressaltam os saberes 
importantes para a docência na área. Quanto à formação de professores para atuar na educação infantil, apoiamo-nos nas pesquisas de Kishimoto (2002) e Kramer (2002), que apontam para os problemas enfrentados por esta área, em especial o fato de não se respeitarem as especificidades da docência nesse nível de ensino.

Inicialmente o texto apresenta dados sobre os aspectos legais relacionados à formação inicial de professores nas licenciaturas. Em seguida, são apresentados e problematizados os dados sobre as licenciaturas analisadas, discutidas as grades curriculares, a caracterização desses cursos e também suas fragilidades no que diz respeito à formação do professor para atuar na educação infantil. Por fim, pontuamos alguns problemas enfrentados no que se refere à docência na educação infantil, refletindo sobre as dificuldades e indefinições acerca do perfil de professor e os desafios impostos à prática pedagógica com as crianças pequenas.

\section{ASPECTOS LEGAIS: EM DISCUSSÃO, AS LICENCIATURAS}

A LDB 9.394/96 prevê em seu artigo 62 que o docente atuante na educação básica poderá obter sua formação em nível superior em curso de licenciatura, graduação plena, sendo admitida a formação em nível médio na modalidade normal. Em termos legais, existe a possibilidade de que a formação de professores para atuar na educação básica ocorra em todas as licenciaturas. Ao não definir um curso específico voltado para a docência, em especial para a educação infantil e os anos iniciais, é possível perceber a fragilidade na formação do professor da educação básica, o que demonstra uma visão de formação polivalente.

Brzezinski (2007) analisa que a LDB trouxe possibilidades e perplexidades. Dentre as possibilidades, a autora ressalta a associação entre teoria e prática como fundamento para a formação do professor e a valorização dos profissionais da educação. No que tange às perplexidades, em sua interpretação, a referida lei ainda não supera a possibilidade de admitir uma formação mínima, referida no artigo 62, em curso de Magistério. 0 aligeiramento e o não aprofundamento que podem decorrer dessa opção contrariam as investigações sobre o "[...] desenvolvimento infantil que comprovam a necessidade de profissionais mais bem preparados, com formação aprofundada para atenderem a faixa etária não afeta a abstrações" (BRZEZINSKI, 2007, p. 159). 
Com a afirmação da Constituição Federal em 1988 de que a educação é um direito social de todos e do reconhecimento da educação infantil como primeira etapa da educação básica, conforme a LDB 9.394/96, é dever do Estado organizar e ofertar o atendimento das crianças pequenas em creches e préescolas. Essa garantia da educação deve considerar padrões de qualidade e o fortalecimento de práticas pedagógicas que promovam o desenvolvimento das crianças pequenas. O Ministério da Educação (MEC), nessa direção, fixou as Diretrizes Curriculares Nacionais da Educação Infantil (DCNEl, 2009) ${ }^{1}$.

O documento foi pensado, elaborado e divulgado com o objetivo de orientar as políticas públicas para a área (Art. 2). Reafirma que o objetivo da educação infantil é o desenvolvimento integral da criança (Art. 3), devendo, para tanto, que as práticas pedagógicas estejam alicerçadas em dois eixos norteadores principais: as interações e as brincadeiras (Art. 9). Nessa direção, as propostas e atividades devem considerar o movimento, as diferentes linguagens expressivas na infância e a diversidade cultural no sentido de promover a ampliação das experiências infantis e a formação humana. Para que essas proposições se efetivem no cotidiano da educação infantil, contudo, são necessários profissionais capazes de pensar e articular uma prática pedagógica que inclua tais orientações e promova efetivamente a aprendizagem e o desenvolvimento infantil.

Nesse sentido, as DCNEI, de caráter mandatório, apontam para um professor capaz de articular as interações vividas pela criança no espaço da instituição, ao valorizar as linguagens e as brincadeiras, ao incentivar que a criança se aproprie de determinadas aprendizagens e, assim, possibilite 0 desenvolvimento na forma de agir, pensar e sentir. Desse modo, cabe saber como os cursos selecionados para essa pesquisa contemplam disciplinas capazes de agregar conhecimentos para o trabalho educacional com as crianças pequenas.

No que se referem à legislação, as licenciaturas objetivam formar professores. Na LDB 9.394/96, o assunto é tratado no Título VI (Dos Profissionais da Educação Básica), abrange os artigos 61 a 67 e volta a ser mencionado no artigo 87 (Disposições Transitórias). Como afirmam Almeida, Ghedin e Leite (2008), sobre a LDB, esta procurou “[...] acolher a ideia da importância e da complexidade do processo de formação de professores e promover mudanças no quadro da formação docente para a Educação Básica no país” (p. 39).

A primeira versão das Diretrizes Curriculares Nacionais para a Educação Infantil foi divulgada em 1998, sendo que em 2009 houve a revisão desse documento. 
Entretanto, segundo as pesquisas de Gatti (2000), as discussões em torno das licenciaturas não ocupam um lugar privilegiado na pauta de discussões dentro das Universidades.

\section{[...] as Licenciaturas dentro das Universidades, públicas ou privadas, raramente são alvo de atenções e projetos. Ao contrário, a formação do professor nunca ocupou lugar privilegiado nas políticas das Universidades, especialmente as públicas, tendo-se tornado, entre as suas atividades, um objetivo de pouco importância (GATTI, 2000, p. 51).}

O lugar pouco privilegiado nas universidades é decorrente do pouco prestígio que as licenciaturas receberam ao longo de sua história nas políticas voltadas à formação de professores.

Para Freitas (2007), os problemas que envolvem a formação de professores não têm soluções fáceis, pois estão envoltos em questões de desigualdade e exclusão próprias do capitalismo. Para ela, as condições perversas que historicamente envolvem a desvalorização da educação e dos professores ainda são bastante elevadas em nosso país.

Em fevereiro de 2002, por meio da Resolução do Conselho Nacional de Educação-CNE/CP n. $1^{2}$, foram instituídas as Diretrizes Curriculares Nacionais para a Formação de Professores da Educação Básica, em nível superior e curso de licenciatura de graduação plena. 0 documento apresenta princípios norteadores amplos, os quais devem ser observados na organização e estruturação dos cursos de formação inicial. Na análise de Almeida, Ghedin e Leite (2008), o espaço dado à prática dentro da matriz curricular dos cursos de formação de professores não poderá ser isolado, restringido apenas ao estágio, desarticulando o restante do curso:

\footnotetext{
Deve estar presente desde o início do curso e permear toda a formação do professor, no interior de todas as disciplinas que constituem os componentes curriculares de formação, e não somente nas disciplinas pedagógicas. Portanto, essa prática deve transcender o próprio estágio, a sala de aula, numa perspectiva interdisciplinar, deve visar ao futuro professor melhor compreensão do ambiente educacional e do contexto escolar [...]

(ALMEIDA; GHEDIN; LEITE, 2008, p. 41).
}

Quanto ao curso de Pedagogia, também licenciatura, as Diretrizes Curriculares Nacionais (DCNP) para o curso de graduação foram instituídas pela Resolução CNE/CP número 1 , de 15 de maio de 2006. O documento dispõe sobre os

\footnotetext{
Atualmente estão em discussão as novas Diretrizes Curriculares Nacionais para a formação inicial em nível superior (cursos de licenciatura, programas e cursos de formação pedagógica para graduados e cursos de segunda licenciatura) e para formação continuada.
} 
princípios curriculares norteadores da formação inicial dos docentes, os quais poderão atuar na educação infantil, nos anos iniciais do ensino fundamental, nos cursos de ensino médio na modalidade normal e em cursos de educação profissional na área de serviços e apoio escolar (Art. 2). O Parecer recomenda que o curso de Pedagogia deva oferecer formação para o exercício integrado e indissociável da docência e da gestão dos processos educativos escolares e não escolares.

Não obstante, as DCNP explicitam que os conhecimentos para atuar na educação infantil deverão ser adquiridos nesse curso de licenciatura. Contudo, a LDB possibilita que os egressos de outros cursos de licenciatura também atuem na docência nas primeiras etapas da educação básica.

\section{LICENCIATURAS E DOCÊNCIA: ANÁLISE DAS GRADES CURRICULARES}

Dado o contexto legal, os cursos de licenciatura devem proporcionar uma formação inicial com conhecimentos voltados para a docência e gestão nas instituições educativas. Como afirma Gatti (2010), devido aos problemas enfrentados atualmente no que diz respeito às aprendizagens escolares, há uma preocupação com as licenciaturas. Preocupação essa que, segundo a autora, não deve recair apenas sobre os professores e a sua formação, mas também nos responsáveis pela gestão e manutenção das redes de ensino.

Ao considerar que a formação inicial dos professores atuantes na educação básica se dá por meio das diversas licenciaturas em instituições de ensino superior e que nas instituições de educação infantil a diversidade quanto ao curso de graduação é verificada, nosso olhar esteve voltado para três cursos de uma instituição pública do estado do Paraná. Embora este estudo tenha suas limitações por debruçar-se apenas sobre três cursos, entendemos que é possível refletir em que medida preparam a contento os profissionais para a docência na educação infantil.

O curso de licenciatura em História da instituição pesquisada possui um total de 3.071 horas e duração de quatro anos, sendo que ao concluir o curso o formando poderá atuar em escolas, faculdades, universidades, institutos, fundações, museus, arquivos históricos, bancos de dados, editoras e assessorias de pesquisa, dentre outras 3 .

As considerações mencionadas no decorrer do texto sobre as licenciaturas de História, Ciências Biológicas e Pedagogia foram coletadas no site da instituição, que disponibiliza as informações atualizadas sobre cada curso. 
Ao analisar a grade curricular do curso, encontramos duas disciplinas que se referem especificamente à formação pedagógica: Psicologia da Educação, com carga horária de 68 horas, ofertada no primeiro ano, e Didática para o Ensino de História, com carga horária de 102 horas, ofertada no segundo ano do curso. Há também as disciplinas voltadas especificamente para a prática de ensino, como o estágio supervisionado, mas esse se concentra nos anos finais do ensino fundamental e no ensino médio. 0 ementário da disciplina de Didática aponta para uma disciplina voltada para o estudo e avaliação crítica dos processos de ensino-aprendizagem, planejamento, currículo e avaliação à luz das diferentes concepções de ensino de História. A disciplina de Psicologia da Educação busca oferecer conhecimentos gerais de como se processa o desenvolvimento humano desde a concepção até a adolescência, além de conceitos e teorias que fundamentam o desenvolvimento humano e a interação professor-aluno-conhecimento. Nas duas disciplinas a ênfase recai sobre conhecimentos genéricos, com carga horária limitada.

Ao observarmos a grade curricular e as informações sobre o curso de História e seu campo de atuação, embora sinalizem que o profissional formado nesta licenciatura possa atuar em escolas, em nenhum momento fazem referência ao trabalho com crianças pequenas. A disciplina de estágio é oferecida no terceiro e quarto anos do curso, com 136 horas em cada ano, sendo que no terceiro ano a intervenção acontece no ensino fundamental nas séries finais e no quarto ano no ensino médio. Concluímos que não há referência sobre as especificidades da docência na educação infantil durante o curso de História, a não ser a intenção da disciplina de Psicologia da Educação em abordar questões relativas ao desenvolvimento infantil.

De modo semelhante, ao analisar a grade curricular do curso de licenciatura em Ciências Biológicas, não encontramos disciplinas que especifiquem o trabalho com crianças pequenas da educação infantil. A Biologia como ciência estuda os seres vivos e abrange um espectro amplo de áreas acadêmicas que estudam a vida nas mais variadas escalas. Como campo de atuação, o biólogo trabalha com o ensino de Ciências e Biologia, com consultoria e assessoramento para empresas, fundações, sociedades e associações de classe, entidades autárquicas, privadas ou públicas, estações experimentais, laboratórios de análises clínicas, industriais e institutos biológicos, bioquímicos e de educação ambiental. Algumas disciplinas destinam parte de sua carga horária aos conhecimentos específicos para atuar na área do ensino, mas não especificam como nem onde serão realizadas essas atividades. Entre as disciplinas optativas, nenhuma delas se refere aos 
conhecimentos específicos de sala de aula. Então, o curso totaliza 3.298 horas com duas disciplinas ofertadas pelo departamento de Pedagogia: Organização e Funcionamento da Educação Básica e Psicologia da Educação, que totalizam 136 horas. Os estágios serão desenvolvidos nas séries finais do ensino fundamental e no ensino médio, com 272 horas para a disciplina de estágio ofertada no quarto ano.

$\mathrm{Na}$ análise da grade curricular para o curso de Pedagogia, com total de 3.213 horas, há 272 horas distribuídas em duas disciplinas que tratam especificamente sobre a educação infantil: Fundamentos da Educação Infantil no primeiro ano e Metodologia da Educação Infantil no segundo, ambas com carga horária de 102 h/a. No primeiro semestre do terceiro ano, um estágio neste nível de ensino, com carga horária de 68 horas, deve contemplar atividades de planejamento e organização do trabalho em sala de aula e mais 52 horas de atividades desenvolvidas entre observação e regência nos centros de educação infantil do município. Entretanto, não fica claro que as demais disciplinas do curso de Pedagogia tratem da especificidade do trabalho na educação infantil, embora nas ementas de algumas apontem de forma abrangente as relações dentro da escola.

Por exemplo, a disciplina Políticas Educacionais, Organização e Funcionamento da Educação Básica, oferecida no terceiro ano, com carga horária de 136 $\mathrm{h} / \mathrm{a}$, prevê estudos sobre os processos de elaboração e implementação das políticas públicas e da legislação educacional. Pelo texto, pressupõe-se que a disciplina deverá propor ampla discussão que inclui a análise das políticas que envolvem desde a educação infantil ao ensino superior, porém não está explícito no ementário. De modo semelhante ocorre com as disciplinas de Psicologia I e II, com carga horária de 102 h/a cada, cursadas no primeiro e segundo anos, respectivamente. Em Psicologia I propõem-se estudos sobre as relações históricas entre a psicologia e a educação, ligadas às principais abordagens e focos da psicologia da educação escolar referente à educação brasileira. Em Psicologia II apresentam-se as teorias psicológicas da aprendizagem e do desenvolvimento: convergências e divergências epistemológicas.

Desse modo é possível observar que a marginalização da educação infantil nas políticas e historicamente se reflete na organização dos cursos em que se sobressai o enfoque para a atuação no ensino fundamental. Assim, a discussão em torno da formação do profissional que irá atender a criança pequena nas instituições de educação infantil ainda carece de aprofundamento nos 
debates. É importante rever aspectos como carga horária e propor que os assuntos relacionados à educação infantil estejam incorporados em todas as disciplinas do curso de Pedagogia, considerando que, segundo as DCNP, a docência é o foco principal do curso (Arts. 2 e 4).

Como comenta Kramer (2002), a educação infantil convive com paradoxos de uma realidade que envolve as diferentes instâncias (federal, estadual e municipal), as quais, mediante suas resoluções e deliberações, muitas vezes estão em conflito com a LDB e as DCNEl e provocam incertezas em relação à formação dos profissionais que atuam nas creches e pré-escolas.

FORMAÇÃO PARA ATUAR NA EDUCAÇÃO INFANTIL: IMPLICAÇÕES PARA A DOCÊNCIA

Ao analisar a organização dos cursos de licenciatura é possível perceber que os problemas que envolvem a definição de uma formação inicial que contemple as especificidades de atendimento e acolhimento da criança de 0 a 5 anos ainda não foram superados, apesar dos avanços propostos no que tange à legislação. Como afirma Kishimoto (2002), “[...] desde tempos passados, acumulam-se os problemas na formação, em decorrência da pouca clareza do perfil desejado nos cursos de formação propostos” (p. 107).

Um olhar atento sobre os cursos de formação de docentes revela que são poucos ou inexistentes os estudos que se debruçam sobre a prática pedagógica. Os estágios, como foi possível observar nas grades curriculares das licenciaturas em História e Ciências Biológicas, não possuem uma carga horária que inclua a educação infantil e os anos iniciais do ensino fundamental, pois se concentram nas experiências com alunos maiores. No curso de Pedagogia percebe-se que as disciplinas específicas que estudam a educação infantil são poucas, o que demostra uma fragilidade na formação do profissional que atuará neste nível de ensino. Há uma tendência a privilegiar a formação para atuar no ensino fundamental.

Isso nos leva a retomar a reflexão inicial no que tange à formação para atuar na educação infantil, pois reconhecemos que a LDB 9.394/96 permite que os profissionais formados nas diversas licenciaturas atuem com as crianças pequenas. Entretanto, como foi possível observar nesta pesquisa, a formação inicial destes não prevê saberes que envolvam o direcionamento do trabalho pedagógico na educação infantil. Mesmo o curso de Pedagogia, que prevê duas disciplinas e um estágio direcionado para a educação infantil, também não dispõe de um tempo adequado junto ao objeto de estudo, ou seja, a 
criança pequena no seu ambiente educativo. Dada a abrangência do perfil profissional proposto pelas DCNP, forma-se um profissional polivalente e impõem-se diversos perfis profissionais. Kishimoto (2002), ao refletir sobre o curso de Pedagogia, ressalta que:

No curso de Pedagogia, um mesmo plano curricular visa formar profissionais para todos os níveis da educação: educação infantil e séries iniciais do ensino fundamental, educação de jovens e adultos, ensino médio, gestores, tecnólogos entre outros, prática que se distancia da ótica profissional (KISHIMOTO, 2002, p. 109).

Nesse sentido, o curso de Pedagogia, mesmo sendo destinado a formar profissionais para a docência na educação infantil, deveria repensar sua organização curricular e seu projeto pedagógico a fim de formar um profissional capacitado a atender a infância, bem como as demais áreas propostas pelas DCNP. Ainda segundo Kishimoto (2002), é necessário pensar uma modalidade de formação que respeite a organização da área da infância, uma "pedagogia da infância" (p. 113).

Entretanto, a discussão em torno do perfil profissional formado pelo curso de Pedagogia está em pauta desde a sua criação e, com a aprovação das DCNP em 2006, o curso assume o compromisso de formar um profissional capaz de atender a primeira etapa da educação básica, como impõe a LDB 9.394/96. Saviani (2007, p. 127), ao problematizar o proposto nas DCNP, coloca:

O resultado nos coloca diante do seguinte paradoxo: as novas diretrizes curriculares nacionais para o Curso de Pedagogia são, ao mesmo tempo, extremamente restritas e demasiadamente extensivas: muito restritas no essencial e assaz excessivas no acessório

Considerando tais reflexões, entendemos que o tão abrangente conceito de qualidade no atendimento das crianças pequenas junto às instituições de educação infantil depende, em grande parte, de uma formação inicial sólida do profissional que está diretamente com elas. Como afirma Leite (2002), ter um profissional formado em nível superior para atender as crianças de 0 e 5 anos é um "desafio". Desafio este que, segundo a autora, está em "[...] rever e reformular os currículos de formação inicial dos profissionais de educação infantil” (p. 195). Ademais, como afirma Kramer (2002), o reconhecimento da especificidade da infância, a valorização dos conhecimentos possuídos por ela e a garantia da aquisição de novos conhecimentos requer a formação de um profissional capaz de reconhecer as características da infância. 
Ao problematizar a formação inicial para atuar na educação infantil, reconhecemos que é necessário investirmais nas especificidades que envolvem o trabalho com as crianças pequenas para que os aspectos relacionados ao fazer pedagógico estejam de fato no centro das discussões, considerando a docência como prioritária. Concordamos com as ideias de Brzezinski (2009), que ressalta que os currículos devem contemplar conhecimentos específicos para a docência na educação infantil, o que permite identificar e refletir sobre os interesses e necessidades das crianças de 0 a 5 anos de idade.

A partir da análise das grades curriculares das licenciaturas em áreas específicas empreendida nessa pesquisa, constatamos que não há disciplinas que tratem sobre os saberes que envolvem a educação infantil e sobre a dinâmica de trabalho presente nos espaços de atendimento da criança pequena.

No que se refere à análise da licenciatura em Pedagogia, reconhecemos o curso como o lócus principal da formação para atuar na educação infantil. Contudo, essa formação oferecida também carece de aprofundamentos que se refletem na insuficiente carga horária e no número de disciplinas atualmente oferecido pelo curso. Faz-se necessário ampliar o leque de disciplinas que tratem dos fundamentos e da organização do trabalho pedagógico para atuar na educação infantil. Considerando que a partir das DCNP, instituídas em 2006, o curso assume em nível superior a formação dos profissionais que atuarão na educação infantil, as poucas disciplinas da grade curricular demonstram um viés generalista com grande ênfase nos conhecimentos teóricos ao não aprofundar questões específicas para o atendimento da criança pequena.

Desse modo, a partir das análises realizadas nas grades curriculares dos cursos de licenciatura, entendemos que a possibilidade afirmada na LDB 9.394/96 de os profissionais advindos dos cursos de licenciaturas atuarem na educação infantil há que ser discutida, de modo a incluir de modo efetivo os saberes docentes necessários ao atendimento da criança pequena nessas grades. Como lembra Brzezinski (2009): “[...] o Brasil é um país de contrastes também no que tange à magnitude das leis” (p. 8).

Superar a fragmentação entre os conhecimentos adquiridos na formação inicial e os conhecimentos necessários para a atuação na educação infantil requer romper com as estruturas curriculares engessadas que concentram esforços em conhecimentos específicos da área de formação sem formar declaradamente 
para a docência. Existe a necessidade de integrar teoria e prática, bem como realizar de fato dentro das universidades a indissociabilidade entre ensino, pesquisa e extensão. Como afirma Gatti (2010):

A formação de professores profissionais para educação básica tem que partir de seu campo de prática e agregar a este os conhecimentos necessários como valorosos, em seus fundamentos e com as mediações didáticas necessárias, sobretudo por se tratar de formação para o trabalho educacional com crianças e adolescentes (GATTI, 2010, p. 1375).

Assim, problematizar a formação inicial proposta nos cursos de licenciatura envolve pensar a prática e a valorização dos professores como um todo, discussão esta que não se esgota nos limites deste trabalho. No que diz respeito ao exercício do magistério na educação infantil contemplado na LDB 9.394/96, concordamos com a postura de perplexidade da pesquisadora Brzezinski (2007), citada anteriormente, em admitir uma formação mínima para essa função. Ademais, problematizar a formação do professor para atuar na educação infantil abre caminhos para pensar quem é a criança e os modos como ela é vista pela sociedade, bem como a maneira como têm sido organizados os espaços onde é atendida. 


\section{Undergraduate licentiates and early childhood education: challenges in initial teacher education}

Abstract: This article presents findings of a research project conducted during 2014 about the relationship between undergraduate initial teacher education and the knowledge acquired in three undergraduate programs in early childhood education. The goal was to determine whether curricula have subjects discussing certain questions regarding early childhood education, as well as to problematize initial teacher education and identify challenges in teaching young children. Overcoming fragmentation in the knowledge acquired in initial teacher education and determining the necessary knowledge for teaching children requires breaking with stiffened curricular structures that concentrate efforts on the knowledge of specific areas without clearly educating for teaching.

Keywords: Undergraduate courses. Teacher education. Early childhood education. 


\section{REFERÊNCIAS}

ALMEIDA, Maria Isabel de; GHEDIN, Evandro; LEITE, Yoshie Ussami Ferrari. Formação de professores: caminhos e descaminhos da prática. Brasília: Líder Livro Editora, 2008.

BRASIL. Lei 9.394/96. Estabelece as Diretrizes e Bases da Educação Nacional, 1996. Disponível em: 〈http://www.planalto.gov.br/ccivil_03/leis/19394.htm〉. Acesso em: 10 nov. 2013.

- CNE/CP 1, de 18 de fevereiro de 2002. Diretrizes Curriculares Nacionais para a Formação de Professores da Educação Básica. 2002. Disponível em: 〈http://portal.mec.gov.br/seesp/arquivos/pdf/res1_2.pdf〉. Acesso em: 10 nov. 2013.

. CNE/CP 1, de 15 de maio de 2006. Diretrizes Curriculares Nacionais para o curso de Graduação em Pedagogia, Licenciatura. Brasília, 2006. Disponível em: 〈http://portal.mec.gov.br/cne/arquivos/pdf/rcp01_06.pdf〉. Acesso em: 10 nov. 2013.

, Ministério da Educação. Secretaria de Educação Básica. Diretrizes Curriculares Nacionais para a Educação Infantil. Brasília, 2010. Disponível em: 〈http://portal.mec.gov.br〉. Acesso em: 10 nov. 2013.

BRZEZINSKI, Iria. Dilemas e desafios nas políticas de formação e de valorização dos profissionais da educação básica. In: SIMPÓSIO BRASILEIRO DA ASSOCIAÇÃO NACIONAL DE POLÍTICAS E ADMINISTRAÇÃO DA EDUCAÇÃO (ANPAE), 26, 2009, Vitória; e CONGRESSO INTERAMERICANO DE POLITICAS E ADMINISTRAÇÃO DA EDUCAÇÃO, 3, 2009, Vitória. Anais...Vitória: ANPAE, 2009. Disponível em: 〈http://www.anpae.org.br/congressos_antigos/ simposio2009/135.pdf〉. Acesso em: 17 set. 2014.

. (Org.). LDB Interpretada: diversos olhares se entrecruzam. 10. ed. São Paulo: Cortez, 2007.

FREITAS, Helena Costa Lopes. A (nova) política de formação de professores: a prioridade postergada. Educação \& Sociedade, Campinas, v. 28, n.100Especial, p. 1203-1230, 2007. Disponível em: 〈http://www.scielo.br/pdf/es/ v31n113/16.pdf $>$. Acesso em: 16 set. 2014.

GATTI, Bernadete. Formação de professores e carreira: problemas e movimentos de renovação. 2. ed. Campinas: Autores Associados, 2000. 
Formação de professores no Brasil: características e problemas. Educação \& Sociedade, Campinas, v. 31, n. 113, p. 1355-1369, 2010. Disponível em: 〈http://www.scielo.br/pdf/es/v31n113/16.pdf〉. Acesso em: 17 ago. 2015.

KISHIMOTO, Tizuko Morchida. Encontros e desencontros na formação dos profissionais de educação infantil. In: MACHADO, Maria Lúcia de (Org.). Encontros e desencontros em educação infantil. São Paulo: Cortez, 2002.

KRAMER, Sonia. Formação de profissionais de educação infantil: questões e tensões. In: MACHADO, Maria Lúcia de (Org.). Encontros e desencontros em educação infantil. São Paulo: Cortez, 2002.

LEITE, Yoshie U.F. Formação dos profissionais em educação infantil: pedagogia x normal superior. In: MACHADO, Maria Lúcia de (Org.). Encontros e desencontros em educação infantil. São Paulo: Cortez, 2002.

SAVIANI, Dermeval. Pedagogia: o espaço da educação na Universidade. CadernosdePesquisa,v.37,n.130,p.99-134,2007.Disponívelem:〈http://www. scielo.br/scielo.php?script=sci_arttext\&pid=S0100-15742007000100006 . Acesso em: 26 mar. 2015.

Sobre a autora:

Simone Maria de Bastos Nascimento é mestranda em Educação pela Universidade Estadual do Centro-Oeste.

simobastos@bol.com.br

Recebido em: setembro de 2015

Aprovado em: outubro de 2015 